Article

\title{
Removal of Acetic Acid from Bacterial Culture Media by Adsorption onto a Two-Component Composite Polymer Gel
}

\author{
Junya Kato ${ }^{1} \mathbb{D}$, Takehiko Gotoh ${ }^{2, * \mathbb{D}}$ and Yutaka Nakashimada ${ }^{1, *}$ \\ 1 Graduate School of Integrated Sciences for Life, Hiroshima University, 1-3-1 Kagamiyama, \\ Higashihiroshima 739-8530, Hiroshima, Japan; junyakato@hiroshima-u.ac.jp \\ 2 Graduate School of Advanced Science and Engineering, Hiroshima University, 1-4-1 Kagamiyama, \\ Higashihiroshima 739-8527, Hiroshima, Japan \\ * Correspondence: tgoto@hiroshima-u.ac.jp (T.G.); nyutaka@hiroshima-u.ac.jp (Y.N.)
}

check for updates

Citation: Kato, J.; Gotoh, T.; Nakashimada, Y. Removal of Acetic Acid from Bacterial Culture Media by Adsorption onto a Two-Component Composite Polymer Gel. Gels 2022, 8, 154. https://doi.org/10.3390/ gels8030154

Academic Editor: Ashleigh Fletcher

Received: 24 January 2022

Accepted: 28 February 2022

Published: 2 March 2022

Publisher's Note: MDPI stays neutral with regard to jurisdictional claims in published maps and institutional affiliations.

Copyright: (C) 2022 by the authors. Licensee MDPI, Basel, Switzerland. This article is an open access article distributed under the terms and conditions of the Creative Commons Attribution (CC BY) license (https:// creativecommons.org/licenses/by/ $4.0 /$ )
Abstract: Organic acids, including acetic acid, are the metabolic products of many microorganisms. Acetic acid is a target product useful in the fermentation process. However, acetic acid has an inhibitory effect on microorganisms and limits fermentation. Thus, it would be beneficial to recover the acid from the culture medium. However, conventional recovery processes are expensive and environmentally unfriendly. Here, we report the use of a two-component hydrogel to adsorb dissociated and undissociated acetic acid from the culture medium. The Langmuir model revealed the maximum adsorption amount to be $44.8 \mathrm{mg}$ acetic acid/g of dry gel at neutral $\mathrm{pH}$ value. The adsorption capacity was similar to that of an ion-exchange resin. In addition, the hydrogel maintained its adsorption capability in a culture medium comprising complex components, whereas the ion-exchange did not adsorb in this medium. The adsorbed acetic acid was readily desorbed using a solution containing a high salt concentration. Thus, the recovered acetic acid can be utilized for subsequent processes, and the gel-treated fermentation broth can be reused for the next round of fermentation. Use of this hydrogel may prove to be a more sustainable downstream process to recover biosynthesized acetic acid.

Keywords: polymer gel; cationic gel; adsorption; organic acid; acetic acid; fermentation; culture medium

\section{Introduction}

Microbial fermentation processes have been widely employed for the production of various chemicals. Microbial fermentation uses biomass as a carbon-neutral resource instead of fossil resources or organic waste, thus providing a promising solution for reducing global carbon emission. Furthermore, some microorganisms can utilize carbon dioxide $\left(\mathrm{CO}_{2}\right)$ and convert it into valuable chemicals [1-7].

Organic acids are produced as metabolites during microbial fermentation. Short-chain volatile fatty acids, especially acetic acid, are common microbial metabolites. They are useful as bulk chemicals in industries and have broad applications in food and pharmaceutical industries [1,2,5,6,8]. Acetic acid has an annual global demand of 10 million tons. Microbial fermentation products currently cover $\sim 10 \%$ of the market, and it is anticipated that the coverage will increase because of low $\mathrm{CO}_{2}$ emission. Among the fermentation processes, the use of acetogens, a group of microorganisms, is advantageous and efficient strategy. The metabolic pathway of acetogens involves the fixation and conversion of $\mathrm{CO}_{2}$ to acetic acid using electrons generated from sugar metabolism or using hydrogen $\left(\mathrm{H}_{2}\right)$. Acetogens can convert sugars into acetic acid without liberating $\mathrm{CO}_{2}$ or even utilize $\mathrm{CO}_{2}$ depending on the energy received from $\mathrm{H}_{2}[9,10]$.

Microbial fermentation is challenged by downstream processes for recovering the biosynthetic products, and acetic acid is no exception. Because acetic acid is released 
into the culture medium in a dilute form and is soluble in an aqueous medium, separation of the acid is difficult. The separation processes, which mostly involve the use of organic solvents, are expensive and have adverse effects on the environment. Nonetheless, alamine/diisobutyl ketone extraction has been shown to reduce global warming potential and fossil fuel usage [6]. Distillation does not require organic solvents but is limited to relatively low-volatile-temperature chemicals. Azeotropic distillation must be used to increase the concentration of acetic acid. However, this process is usually applied for acetic acid concentrations higher than that obtained in fermentation, is energy-intensive, and requires further development [11,12]. Product separation is vital for achieving the purity and concentration required in subsequent industrial processes and for obtaining high productivity and titer in the fermentation process. Fermentation products often have inhibitory effects on the metabolism of microorganisms, thereby limiting the fermentation titer. Acetic acid has also been reported to inhibit microbial activity, and the inhibitory effect originates from disrupted intracellular homeostasis, and not just by a low $\mathrm{pH}$ [13]. This inhibitory effect has also been observed for other organic acids, such as propionic acid $[8,14]$. It is important to remove acetic acid to maintain the microbial performance.

In this study, we attempted to separate acetic acid from the fermentation culture medium using a hydrogel polymer. Hydrogel polymers have attracted attention over the years because of their reasonable capacity and selectivity for removing hazardous materials, such as metals from industrial wastewater [15-18]. Because fermentation culture media change properties, such as the $\mathrm{pH}$, throughout the fermentation process and have complex components, treatment with a hydrogel polymer could facilitate the removal of the desired component. We also tested whether the removed acetic acid, which is harmful for microorganisms, can be recovered using a simple method as a valuable material for industrial applications. The hydrogel-treated medium was examined for its reuse as a culture medium. The hydrogel itself could be easily separated from the culture medium. Therefore, this study can contribute to the development of a process with low environmental burden.

\section{Results and Discussion}

\subsection{Concept of Two-Component Copolymer Gel for Acetic Acid Adsorption}

Acetic acid is a carboxylic acid with two carbon atoms and a $\mathrm{p} K_{\mathrm{a}}$ value of 4.8. Depending on the $\mathrm{pH}$, it exists in the ionized or undissociated form in an aqueous medium. We aimed to capture both the forms of acetic acid from the culture medium over a range of $\mathrm{pH}$, including the $\mathrm{pH}$ at which acid production lowers the $\mathrm{pH}$. Two types of acrylamide monomers were selected to capture each form: $N$-[3-(dimethylamino)propyl]acrylamide, methyl chloride quaternary (DMAPAA-Q) and $N, N$-dimethylamino propylacrylamide (DMAPAA). DMAPAA-Q served as an adsorbent to capture the dissociated acetate ions, and DMAPAA served as an adsorbent to capture the undissociated acetic acid and dissociated protons (Figure 1). A copolymer with equal amounts of these two monomers was synthesized and is referred to as AQ11.

\subsection{Basic Characteristic of Acetic Acid Adsorption on AQ11}

We tested the adsorption of acetic acid on the AQ11 gel at various concentrations of acetic acid (mainly acetate) solution at $\mathrm{pH}$ 7.0. The solution primarily contained acetic acid; the sodium ions present in the medium were derived from $\mathrm{pH}$ adjustment. We examined the basic characteristics at neutral $\mathrm{pH}$ because this $\mathrm{pH}$ is maintained in most of the controlled fermentation processes. The AQ11 gel adsorbed acetic acid, and the corresponding adsorption isotherm (Figure 2) revealed the saturation of adsorption at acetic acid concentrations between 10 and $20 \mathrm{~g} / \mathrm{L}$. Because the saturation concentration was below that required for microbial growth inhibition $(\sim 48 \mathrm{~g} / \mathrm{L})$, as reported for the acetogenic bacterium, Moorella thermoacetica [13], the AQ11 gel would exhibit maximum capacity when the acetic acid is to be recovered in practice. Fit of the data $\left(R^{2}=0.98\right)$ to the Langmuir equation (Equation (1)) suggested that the maximum acetic acid adsorbed by 
AQ11 was $44.8 \mathrm{mg} / \mathrm{g}$ of gel. $\mathrm{K}_{\mathrm{b}}$ was calculated as 0.91 (Figure $\mathrm{S} 1$ ). The fit is consistent with that reported in previous studies on the adsorption of arsenic by DMAPAA-Q [15,19].

$$
\mathrm{C}_{\mathrm{e}} / \mathrm{Q}_{\mathrm{e}}=1 /\left(\mathrm{K}_{\mathrm{b}} \mathrm{Q}_{\max }\right)+\mathrm{C}_{\mathrm{e}} / \mathrm{Q}_{\max }
$$
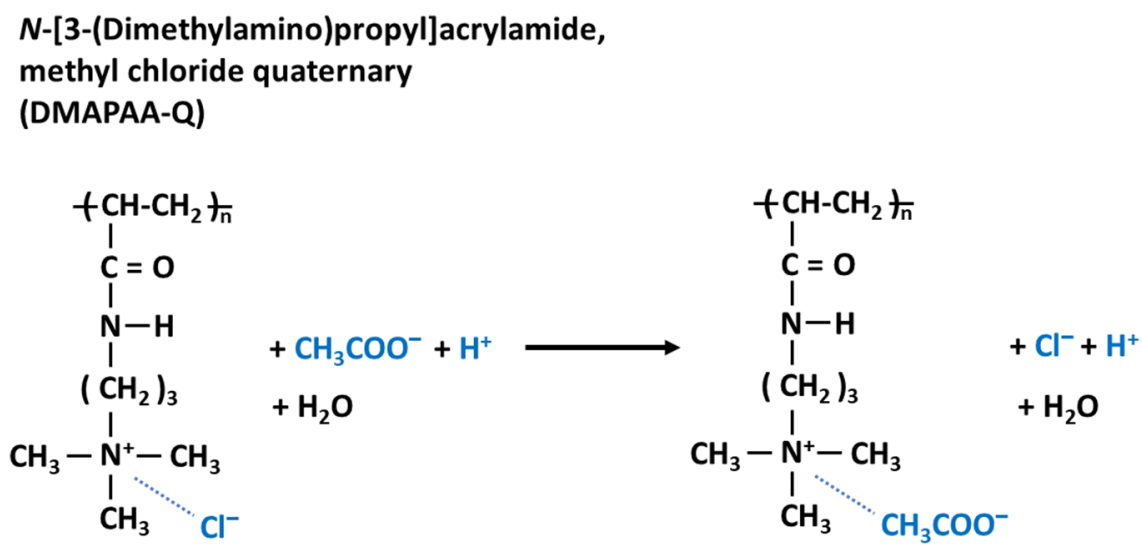

\section{$N, N$-Dimethylamino propylacrylamide (DMAPAA)}
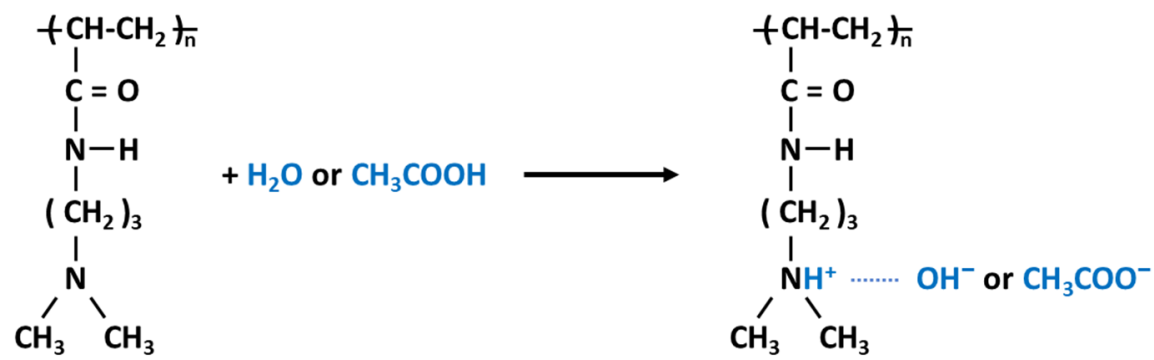

Figure 1. Chemical structures of two types of acrylamide-based polymers in the AQ11 copolymer gel. DMAPAA-Q is enriched with chloride ions $\left(\mathrm{Cl}^{-}\right)$. DMAPAA is enriched with a water molecule when acetic acid is absent. The plausible interactions are shown.

Here, $\mathrm{C}_{\mathrm{e}}$ is the concentration of acetic acid $(\mathrm{g} / \mathrm{L})$ at equilibrium, $\mathrm{Q}_{\mathrm{e}}$ is the adsorption capacity of the AQ11 gel (mg/g-gel), $K_{b}$ is the adsorption coefficient, and $Q_{\max }$ is the maximum adsorption amount.

Next, we measured the time required to reach the adsorption equilibrium at an acetic acid concentration of $10 \mathrm{~g} / \mathrm{L}$. Although we tested the basic adsorption characteristics through overnight reactions, in practical use, the reaction time is a key factor when employing polymer gels for acetic acid removal. The experimental setup was the same as that shown in Figure 2. However, the solution in which AQ11 was immersed was sampled at various time points, and the acetic acid concentration was measured (Figure 3). The acetic acid concentration decreased immediately after the gel was added, and the adsorption initially increased over time. Up to $30 \mathrm{~min}$, the amount adsorbed was more than the saturation amount, with significant variation among the samples collected at different time points. This may indicate non-specific binding to the gel up to $30 \mathrm{~min}$. After $30 \mathrm{~min}$, the adsorbed amount decreased, and the adsorption was near saturation. This trend indicates that a certain time period is required for stable and specific adsorption. Stable adsorption 
requires approximately $30 \mathrm{~min}$, and this reaction time will be reasonably short for practical use.

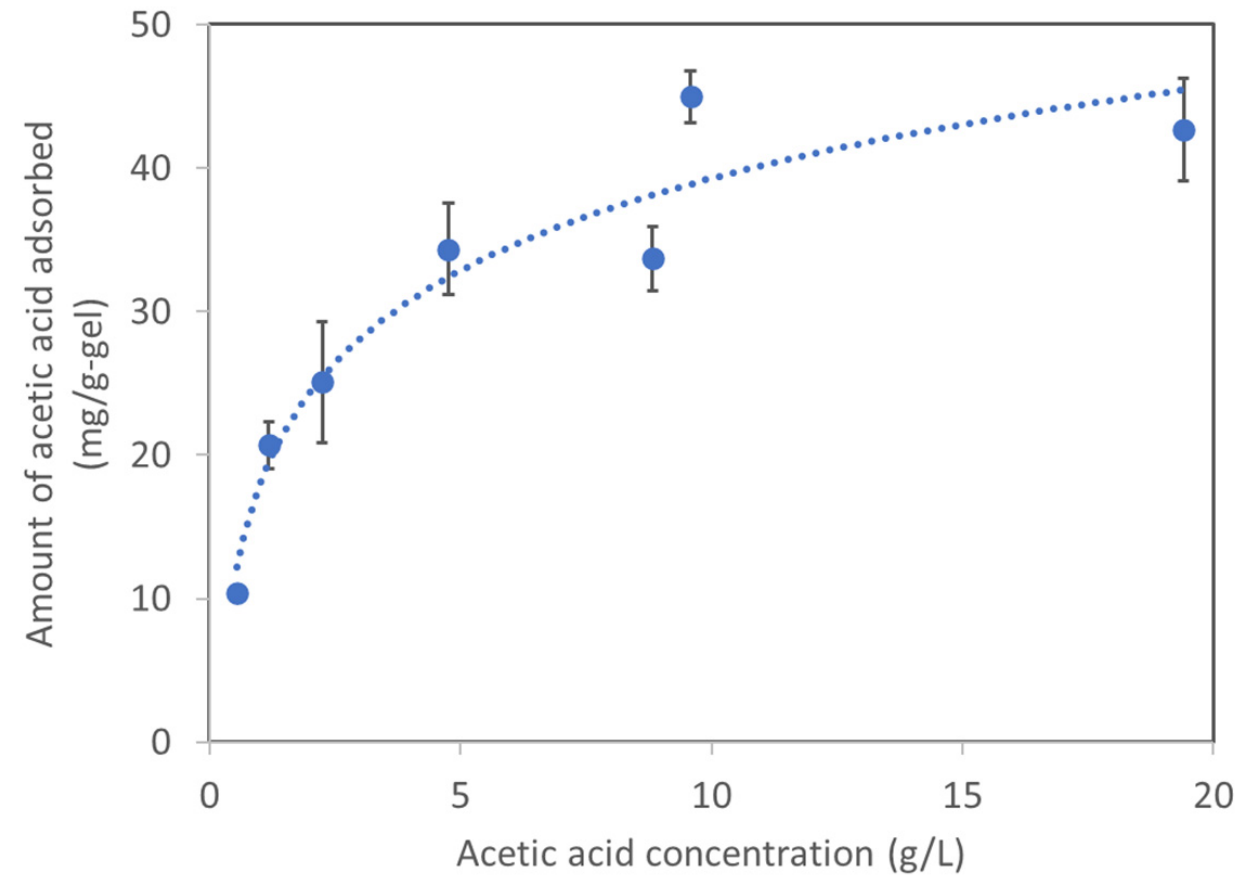

Figure 2. Adsorption isotherm of AQ11 against various concentrations of acetic acid at pH 7.0.

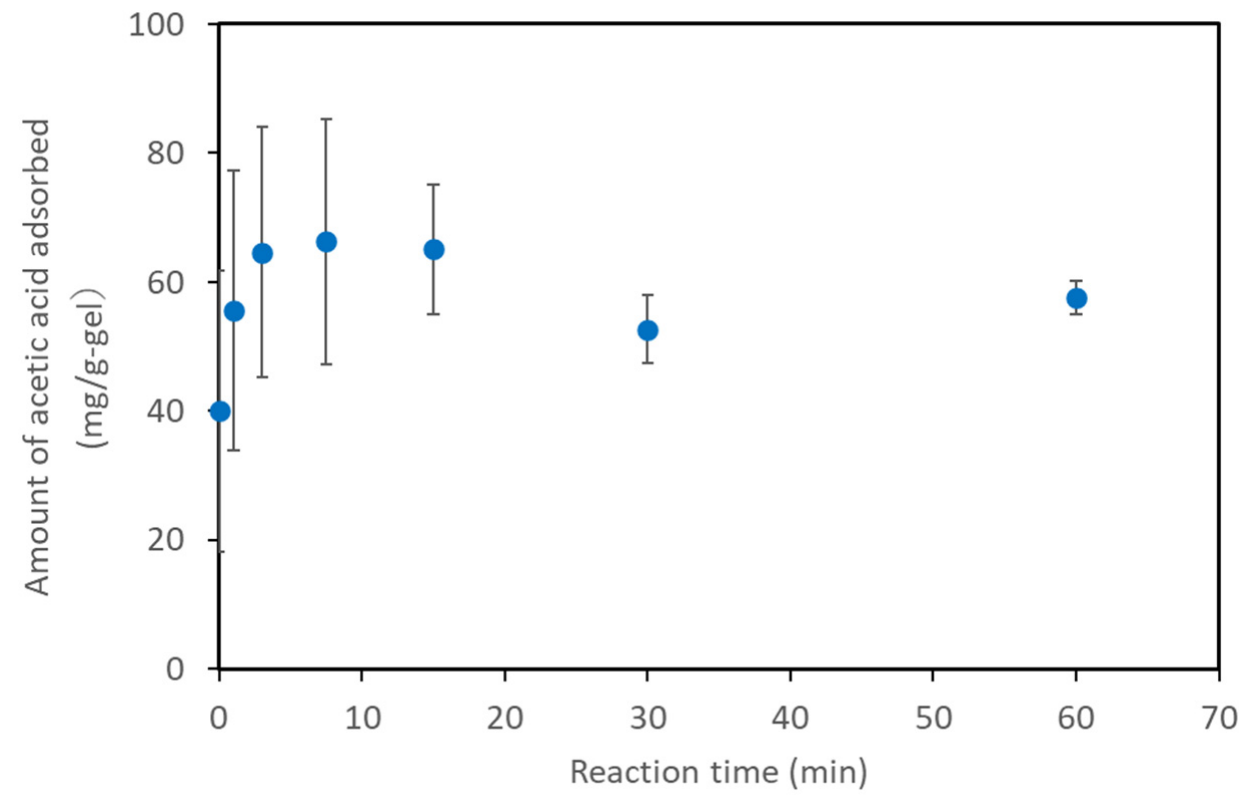

Figure 3. Relationship between the reaction time and amount adsorbed.

\subsection{Comparison of AQ11 with Other Adsorbents}

We compared the adsorption capacity of some selected adsorbents to determine whether AQ11 is superior to other adsorbents. We selected cation exchange and anion exchange resins for comparison: PK208 is a strongly acidic cation exchange resin, and PA312 is a strongly basic anion exchange resin. As expected, PK208 did not adsorb acetic acid because acetate ions are negatively charged and do not bind to cation exchange resins. On the other hand, the adsorption on PA312 was $12 \%$ higher than that on AQ11 in a $10 \mathrm{~g} / \mathrm{L}$ acetic acid solution ( $\mathrm{pH} 7.0$; Figure $4 \mathrm{a}$ ). The acetic acid adsorption on PA312 was 
consistent with the product data sheet [20], which indicates $1.2 \mathrm{meq} / \mathrm{mL}$ of the adsorbent of the minimum salt splitting capacity; at least $40 \mathrm{mg}$ of acetic acid can be captured by one gram of the PA312 resin, considering $1 \mathrm{~g}$ of the resin was equivalent to $1.8 \mathrm{~mL}$ in the assay solution. The use of ion-exchange resins is one of the most common adsorption methods for organic acid recovery [21]. However, in practice, organic acids, including acetic acid, are recovered from solutions that have inconsistent properties. The target solution, the microbial culture broth, has complex properties with complex components and various $\mathrm{pH}$ values. Some of the attempts to recover acetic acid using ion exchange resins have not been completely successful because of the presence of impurities, and the pretreatment steps required [22]. Therefore, we examined the adsorption under various conditions.

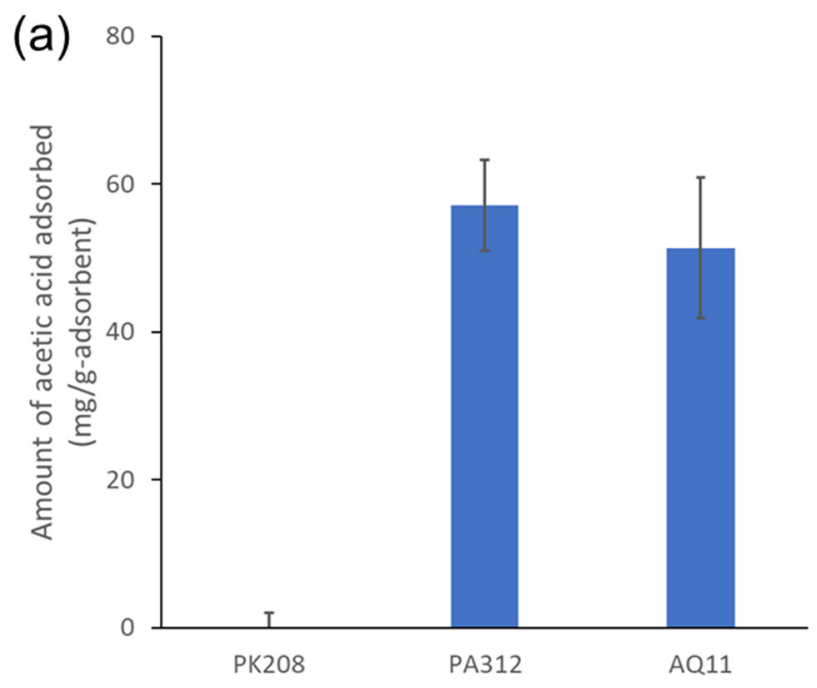

(b)

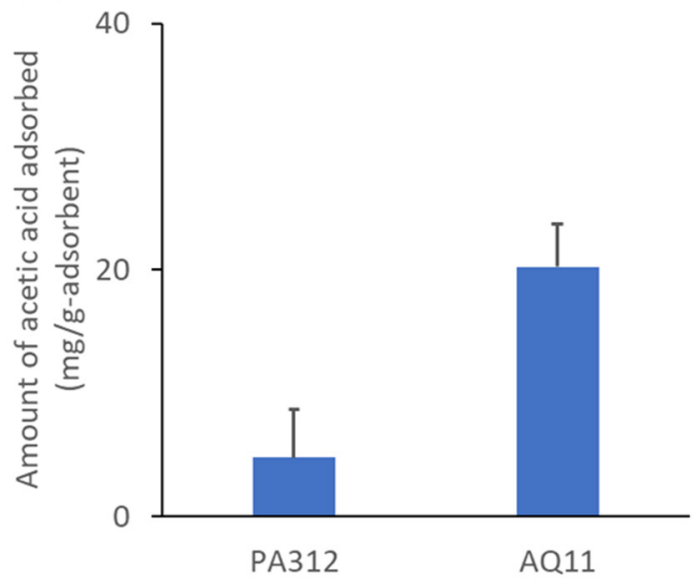

(c)

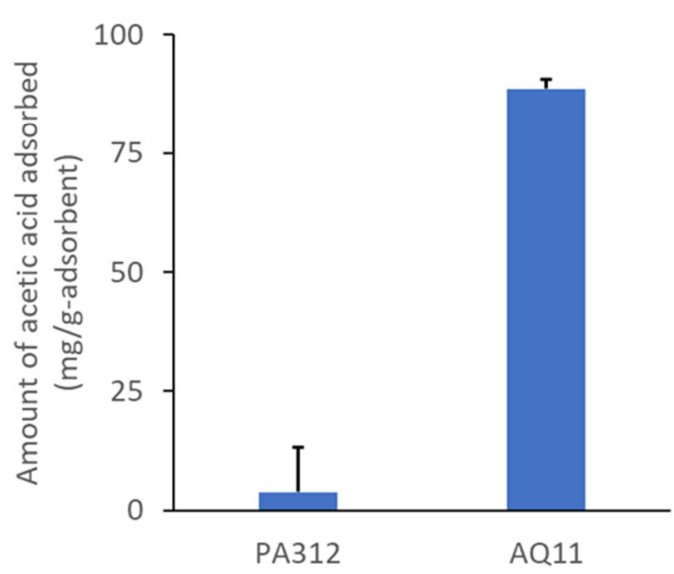

Figure 4. Comparison of adsorption by AQ11 and ion exchange resins. (a) Comparison of PK208, PA312, and AQ11 in a $10 \mathrm{~g} / \mathrm{L}$ acetic acid solution at pH 7.0. (b) Comparison of PA312 and AQ11 in a culture medium. (c) Comparison of PA312 and AQ11 in an acetic acid solution $(10 \mathrm{~g} / \mathrm{L})$ without adjusting the $\mathrm{pH}$ (the $\mathrm{pH}$ of the solution was 2.9).

\subsection{Adsorption Capability of AQ11 in a Culture Medium and at Various $p H$ Values}

We first examined the adsorption in a culture medium for selectivity. We tested the culture medium for the acetogenic bacterium, Acetobacterium woodii. Acetic acid (10 g/L) was added to a fresh culture medium to compare the adsorption capacities of PA312 and AQ11. In this case, PA312 exhibited almost no adsorption, whereas AQ11 maintained its adsorption capability (Figure $4 \mathrm{~b}$ ). Although acetic acid was the main component in this culture medium, the adsorption of acetic acid on PA312 was inhibited by the components in 
the culture medium. Thus, AQ11 was superior to PA312 in terms of selectivity in solutions containing impurities, such as a bacterial culture medium.

We also evaluated the binding capacity at lower $\mathrm{pH}$. At a lower $\mathrm{pH}$, acetic acid exists in an undissociated form, and the ionic interactions required for adsorption are absent. The DMAPAA component of the AQ11 polymer can capture undissociated acetic acid (Figure 1). We tested the adsorption capacity in an acetic acid solution without adjusting the $\mathrm{pH}$ (Figure 4c). PA312 showed almost no binding, as predicted, whereas the adsorption on AQ11 was nearly two-fold higher than that at neutral pH. Thus, AQ11 can tolerate low $\mathrm{pH}$ values for adsorbing acetic acid.

Furthermore, AQ11 maintained its adsorption capacity at various $\mathrm{pH}$ values (Figure 5). The adsorption was tested from $\mathrm{pH} 3.0$ to 10.0, with one unit increment in $\mathrm{pH}$. Interestingly, high adsorption was observed between $\mathrm{pH} 3.0$ and 5.0. Adsorption was also observed in the $\mathrm{pH}$ range of 6.0-10.0, although it was lower than that at low $\mathrm{pH}$ values. This is consistent with the chemical nature of acetic acid, which has a $\mathrm{p} K_{\mathrm{a}}$ value of 4.8. AQ11 shows higher adsorption toward acetic acid at a low $\mathrm{pH}$; more than $50 \%$ of the acetic acid exists in the undissociated form between $\mathrm{pH} 3.0$ and 5.0, whereas a major proportion $(>90 \%)$ of the acid was in the dissociated form between $\mathrm{pH} 6.0$ and 10.0. DMAPAA-Q and DMAPAA adsorbed the dissociated acetate ions and undissociated acetic acid under the former condition, whereas DMAPAA-Q mainly adsorbed the dissociated acetate ions under the latter condition. The $\mathrm{pH}$-dependent adsorption can be attributed to the difference in the adsorption capacities of DMAPAA-Q and DMAPAA.

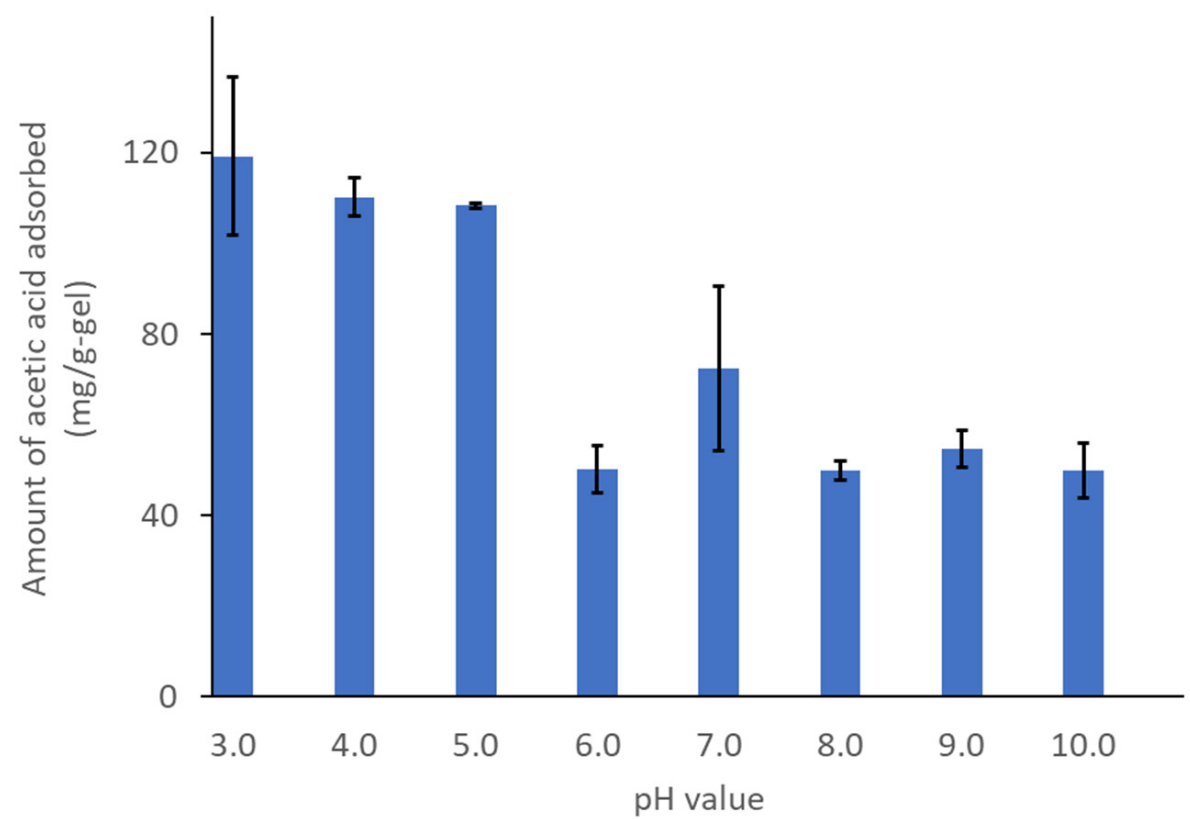

Figure 5. Comparison of the adsorption in acetic acid $(10 \mathrm{~g} / \mathrm{L})$ at various $\mathrm{pH}$.

\subsection{Recovery of Acetic Acid from AQ11}

The recovery of acetic acid from the gel is necessary to utilize the adsorbed acetic acid for industrial applications. The recovery process must be rapid and involve only simple treatment steps. We used a sodium chloride $(\mathrm{NaCl})$ solution to desorb the acetic acid from the gel. The AQ11 gel with adsorbed acetic acid was extensively washed with water before the desorption experiment. The gel was then immersed in water and in $0.1,0.6$, and $3.0 \mathrm{M}$ $\mathrm{NaCl}$ solution (Figure 6). While no desorption of acetic acid was observed in water, acetic acid was desorbed and hence, detected in the $\mathrm{NaCl}$ solutions. We sampled the solutions over time and found that acetic acid was desorbed in the $\mathrm{NaCl}$ solution in a dose-dependent manner and that the desorbed amount increased over time. This trend was apparent in the case of $0.6 \mathrm{M} \mathrm{NaCl}$; the maximum release was observed at $30 \mathrm{~min}$. Among all three $\mathrm{NaCl}$ concentrations, the maximum release upon immersion of the gel was immediately 
observed in the $3.0 \mathrm{M} \mathrm{NaCl}$ solution. Complete release was not observed after $1 \mathrm{~h}$ in $0.1 \mathrm{M}$ $\mathrm{NaCl}$. The released acetic acid in the $0.1 \mathrm{M} \mathrm{NaCl}$ solution was measured after two days; yet the value increased slightly and did not reach the maximum. Therefore, we concluded that a high concentration of $\mathrm{NaCl}(3.0 \mathrm{M})$ or incubation for half an hour in a $0.6 \mathrm{M} \mathrm{NaCl}$ solution was sufficient for the desorption of the adsorbed acetic acid.

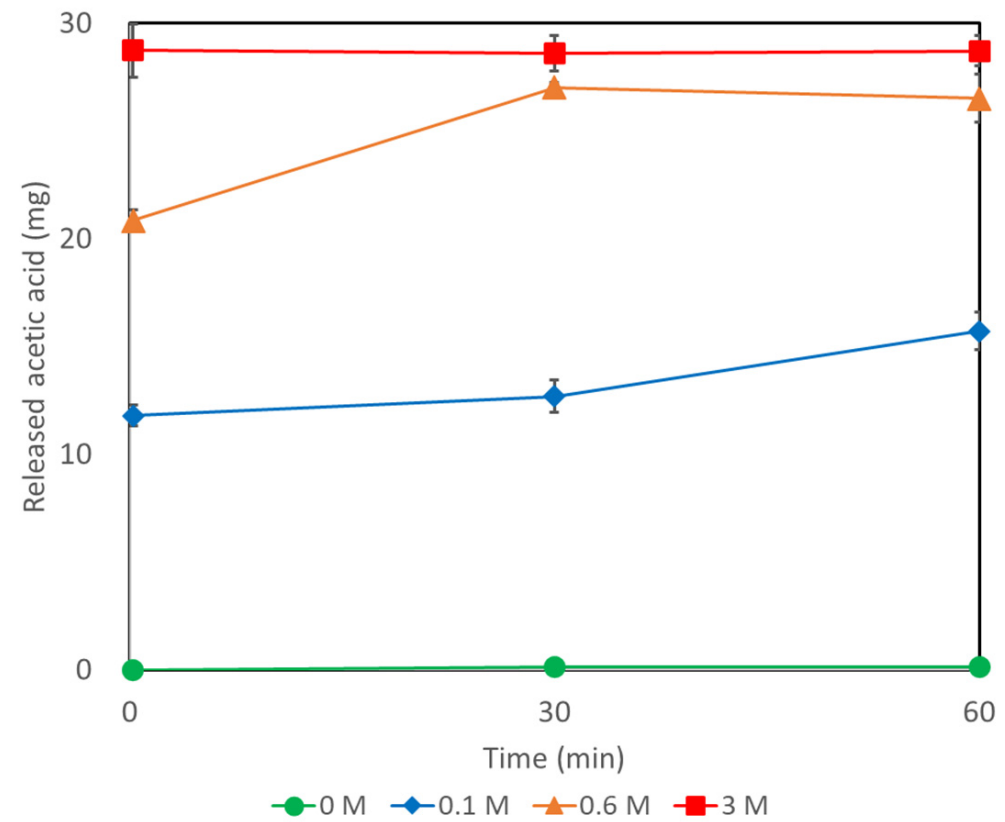

Figure 6. Desorption of the adsorbed acetic acid from AQ11 in $\mathrm{NaCl}$ solutions.

Thus far, desorption after adsorption has been challenging because a considerable amount of acid/alkaline agents or alcohols is required [23,24]. Our study demonstrates an environmentally friendly, simple, and short-term method for the desorption of acetic acid. The recovered acetic acid is suitable for biological processes, such as fermentation using marine bacteria [25]. The $\mathrm{NaCl}$ concentration used for desorption $(0.6 \mathrm{M})$ was close to the $\mathrm{NaCl}$ concentration in seawater.

\subsection{Recycling of AQ11-Treated Culture Broth for Fermentation}

We tested whether the culture medium after AQ11 treatment could be recycled for fermentation. If AQ11 has no harmful effects on the microbial activity during fermentation, recycling can render the process more sustainable with less water consumption. As a test case, we examined the fermentation of acetic acid from sugar using $A$. woodii. The culture broth to be tested was prepared by growing $A$. woodii in a medium supplemented with $10 \mathrm{~g} / \mathrm{L}$ fructose, followed by treatment with AQ11 after complete conversion of fructose to acetic acid. The bacterial cells were removed by centrifugation and filtration before AQ11 treatment. A fermentation experiment was then conducted by using the recycled medium instead of a part of water to prepare the culture medium. As shown in Table 1, the culture with the recycled medium showed comparable conversion of the substrate to the product. Moreover, AQ11 treatment did not have harmful effects on the microbial activity.

Table 1. Comparison of the fermentation profile of $A$. woodii using a fresh medium and a reused medium after treatment with AQ11.

\begin{tabular}{ccc}
\hline Medium Composite & Fructose Consumption $(\mathbf{m M})$ & Acetic Acid Production (mM) \\
\hline Fresh medium & $57.4 \pm 0.4$ & $108.1 \pm 3.2$ \\
Recycled medium & $56.5 \pm 1.1$ & $111.6 \pm 3.1$ \\
\hline
\end{tabular}




\subsection{Adsorption of Short-Chain Organic Acids by AQ11}

Finally, we assessed the possibility of applying AQ11 to separate other short-chain organic acids. Organic acids with different chain lengths, namely, formic acid (C1), acetic acid (C2), propionic acid (C3), and butyric acid (C4), were selected. Each acid solution was prepared at concentrations between 160 and $200 \mathrm{mM}$, and the $\mathrm{pH}$ was adjusted to 7.0. The organic acids were adsorbed onto AQ11 either with similar adsorption capacity or with a slightly higher capacity (up to 30\% more molecules) (Table 2). Thus, the AQ11 gel can also be used to separate different types of organic acids. These organic acids are in a group of volatile fatty acids (VFAs) produced by fermentation and are useful in industries [26].

Table 2. Comparison of the adsorption on the AQ11 gel toward various organic acids.

\begin{tabular}{ccc}
\hline Organic Acid & Tested Concentration $(\mathbf{m M})$ & $\begin{array}{c}\text { Amount Adsorbed } \\
\text { (mmol/g-gel) }\end{array}$ \\
\hline Formic acid & 160 & $0.88 \pm 0.07$ \\
Acetic acid & 162 & $0.67 \pm 0.08$ \\
Propionic acid & 178 & $0.75 \pm 0.03$ \\
Butyric acid & 193 & $0.80 \pm 0.09$ \\
\hline
\end{tabular}

\section{Conclusions}

This study shows that the two-component composite copolymer AQ11 effectively separates and recovers acetic acid from a microbial culture medium. AQ11 is superior to ionexchange resins in selectively capturing acetic acid with a high capacity from an aqueous medium containing complex components. The recovery of acetic acid by desorption requires a simple process and a short reaction time, which are suitable for industrial applications. Furthermore, the treated medium can be recycled for subsequent culturing. Thus, the use of AQ11 may serve as a sustainable post-fermentation method.

\section{Materials and Methods}

\subsection{Materials}

Monomeric DMAPAA-Q and DMAPAA were obtained from KJ Chemicals Corporation (Tokyo, Japan). Potassium dichromate $\left(\mathrm{K}_{2} \mathrm{Cr}_{2} \mathrm{O}_{7}\right)$ and $N, N, N^{\prime}, N^{\prime}$-tetramethylethylenediamine (TEMED) were obtained from Nacalai Tesque, Inc. (Kyoto, Japan). $N, N^{\prime}$-methylenebisacrylamide (MBAA) and ammonium peroxodisulfate (APS) were obtained from Sigma Aldrich Co. (St. Louis, MO, USA). All reagents were used as received. Aqueous solutions were prepared using distilled water. PK208 and PA312 were purchased from Mitsubishi Chemical Corporation (Tokyo, Japan). Organic acids were purchased from Nacalai Tesque, Inc. (Kyoto, Japan). A. woodii is a type strain DSM 1030.

\subsection{Synthesis of Hydrogel Adsorbent}

In a $30 \mathrm{~mL}$ volumetric flask, $3.617 \mathrm{~g}$ of DMAPAA-Q (monomer), $1.841 \mathrm{~g}$ of DMAPAA (monomer), $0.2698 \mathrm{~g}$ of MBAA (cross-linking agent), and $0.08135 \mathrm{~g}$ of TEMED (accelerator) were dissolved in distilled water. APS (initiator, $0.15973 \mathrm{~g}$ ) was dissolved in distilled water in a $5 \mathrm{~mL}$ volumetric flask (Table 3). Nitrogen gas $\left(\mathrm{N}_{2}\right)$ was purged for $30 \mathrm{~min}$ in each solution to remove oxygen $\left(\mathrm{O}_{2}\right)$ and prevent the inhibition of radical polymerization in the flask containing distilled water. After $\mathrm{N}_{2}$ purging, the initiator and monomer solutions were mixed and stirred for $20 \mathrm{~s}$ and then charged into a Teflon pipe with an inner diameter of $6 \mathrm{~mm}$. The DMAPAA-Q, DMAPAA, and MBAA were polymerized at $25^{\circ} \mathrm{C}$ for $6 \mathrm{~h}$. After polymerization, the gel was removed from the pipe and cut into pieces of $6 \mathrm{~mm}$ length. The gel was washed with methanol for $24 \mathrm{~h}$ using a Soxhlet extractor (Asahi Glassplant Inc., Arao City, Japan) to remove the unreacted monomers. After washing, the gel was dried at $25^{\circ} \mathrm{C}$ for several days and then thoroughly dried in an oven at $50{ }^{\circ} \mathrm{C}$. After drying, the gel was a solid and crushed. Pieces with diameters of approximately $1 \mathrm{~mm}$ were selected 
to perform the adsorption studies. The solid form becomes a gel, once it is immersed in aqueous solutions.

Table 3. Synthesis condition of the AQ11 hydrogel.

\begin{tabular}{ccccc}
\hline Component Name & Component Type & Molecular Weight & $\mathbf{m o l} / \mathbf{m}^{\mathbf{3}}$ & $\mathbf{g}$ \\
\hline DMAPAA & monomer & 105.22 & 500 & 1.841 \\
DMAPAA-Q & monomer & 206.71 & 500 & 3.617 \\
MBAA & linker & 154.17 & 50 & 0.2698 \\
TEMED & accelerator & 116.21 & 20 & 0.08135 \\
APS & Initiator & 228.19 & 20 & 0.15973 \\
\hline
\end{tabular}

\subsection{Analytical Methods}

The organic acid and fructose concentrations were measured by high performance liquid chromatography (HPLC). The chromatograph (LC-2000 Plus HPLC; Jasco, Tokyo, Japan) equipped with a refractive index detector (RI-2031 Plus; Jasco), Shodex RSpak KC811 column (Showa Denko, Kanagawa, Japan), and Shodex RSpak KC-G guard column (Showa Denko). The column temperature during the analysis was $60^{\circ} \mathrm{C}$. Ultrapure water containing $0.1 \%(v / v)$ phosphoric acid was used as the mobile phase at a flow rate of $0.7 \mathrm{~mL} / \mathrm{min}$. Crotonic acid was used as the internal standard [27]. The experiments were performed in triplicate, and the standard deviations are shown.

\subsection{Adsorption Assay}

In the adsorption experiment, $0.5 \mathrm{~g}$ or $1.0 \mathrm{~g}$ of the AQ11 gel was dispensed into a $50 \mathrm{~mL}$ tube. The $\mathrm{pH}$-controlled organic acid solution was prepared using the organic acid to be tested, sodium salt of organic acid, and $\mathrm{NaOH}$. Sodium formate, sodium acetate, sodium propionate, or sodium butyrate was dissolved in water, and the $\mathrm{pH}$ was adjusted by using the corresponding organic acid or $\mathrm{NaOH}$, respectively. For acidic $\mathrm{pH}$ to test the adsorption of acetic acid, acetic acid was dissolved in water and the $\mathrm{pH}$ was adjusted by $\mathrm{NaOH}$. Adsorption was initiated by adding $20 \mathrm{~mL}$ of the corresponding organic acid solution to each tube and shaking it at $180 \mathrm{rpm}$ in a shaker at $30^{\circ} \mathrm{C}$. The mixture was incubated overnight (for 20-24 h) to establish equilibrium unless otherwise noted. The organic acid concentration was measured using HPLC before and after the adsorption. The amount of adsorbed organic acid was calculated using the following equation:

$$
\mathrm{Q}=\left(\mathrm{C}_{0}-\mathrm{C}_{\mathrm{v}}\right) \times \mathrm{V} \times M / \mathrm{m}
$$

Here, $\mathrm{Q}$ is the amount of organic acid adsorbed (g/g-adsorbent), $\mathrm{C}_{0}$ is the initial concentration of organic acid ( $\mathrm{mol} / \mathrm{L}), \mathrm{C}_{\mathrm{V}}$ is the equilibrium concentration or the concentration after adsorption reaction, $\mathrm{V}$ is the volume of organic acid solution used for the reaction, $\mathrm{m}$ is the mass of adsorbent ( $\mathrm{g}$ ) in a dry form, and $M$ is the molar mass of organic acid.

\subsection{Desorption Assay}

Desorption of acetic acid or acetate ions adsorbed onto AQ11 gel was studied in $\mathrm{NaCl}$ solutions. The acetic acid solution, with $\mathrm{pH}$ adjusted to 7.0, was removed by centrifugation at $2000 \mathrm{rpm}$ after adsorption. The gel was washed with an equal amount of deionized water to that of the acetic acid solution, separated, and removed by centrifugation. The gel was then washed three times. An $\mathrm{NaCl}$ solution, whose volume was the same as that of the acetic acid solution, was then added to the gel to initiate desorption. One milliliter of $\mathrm{NaCl}$ solution was sampled over time, and the concentration of acetic acid was measured by HPLC. The amount of acetic acid desorbed was calculated using the following equation:

$$
\mathrm{Q}^{\prime}=\mathrm{C}_{\mathrm{v}}^{\prime} \times \mathrm{V}^{\prime} \times \mathrm{M} / \mathrm{m}
$$


Here, $Q^{\prime}$ is the amount of acetic acid released (g acetic acid/g gel), $\mathrm{C}_{\mathrm{v}}^{\prime}$ is the concentration of acetic acid in the $\mathrm{NaCl}$ solution, $\mathrm{V}^{\prime}$ is the volume of the $\mathrm{NaCl}$ solution at the time of sampling, $\mathrm{m}$ is the mass of adsorbent $(\mathrm{g})$, and $\mathrm{M}$ is the molar mass of acetic acid.

\subsection{Fermentation Experiment}

The culture medium for growing A. woodii was prepared following the protocol for the acetogen Moorella thermoacetica; however, the concentration of $\mathrm{NaHCO}_{3}$ was different [28]. An $\mathrm{NaHCO}_{3}$ stock solution $(100 \mathrm{~g} / \mathrm{L})$ was prepared and added to achieve a final concentration of $10 \mathrm{~g} / \mathrm{L}$. Briefly, a modified ATCC 1754 PETC medium [29] was prepared for the cultures as follows: the basal medium contained: $10.0 \mathrm{~g} / \mathrm{L}$ fructose, $2.0 \mathrm{~g} / \mathrm{L}$ yeast extract, $1.2 \mathrm{~g} / \mathrm{L} \mathrm{L}$-cysteine hydrochloride monohydrate, $1.0 \mathrm{~g} / \mathrm{L} \mathrm{NH}_{4} \mathrm{Cl}, 0.1 \mathrm{~g} / \mathrm{L} \mathrm{KCl}, 0.2 \mathrm{~g} / \mathrm{L}$ $\mathrm{MgSO}_{4} \cdot 7 \mathrm{H}_{2} \mathrm{O}, 0.8 \mathrm{~g} / \mathrm{L} \mathrm{NaCl}, 0.1 \mathrm{~g} / \mathrm{L} \mathrm{KH}_{2} \mathrm{PO}_{4}, 0.02 \mathrm{~g} / \mathrm{L} \mathrm{CaCl} 2 \cdot 2 \mathrm{H}_{2} \mathrm{O}, 10.0 \mathrm{~g} / \mathrm{L} \mathrm{NaHCO}$, $10 \mathrm{~mL}$ of trace elements, $10 \mathrm{~mL}$ of Wolfe's vitamin solution [30], and $1.0 \mathrm{mg}$ of resazurin/L of deionized water. The medium was prepared, and $A$. woodii was grown anaerobically [31]. A. woodii was grown in $125 \mathrm{~mL}$ glass vials at $30^{\circ} \mathrm{C}$ in $50 \mathrm{~mL}$ of the culture medium dispensed. Fructose consumption and acetic acid production were monitored by sampling $1 \mathrm{~mL}$ of the culture, followed by HPLC analysis. To reuse the culture broth after AQ11 treatment, $10 \mathrm{~g}$ of the gel was used to remove acetic acid from one vial of the culture broth $(\sim 45 \mathrm{~mL})$. The gel was then removed by filtration and centrifugation. The clear broth was sterilized by filtration, followed by $\mathrm{N}_{2}$ purging to remove $\mathrm{O}_{2}$. The recycled medium was prepared by supplementing with the broth instead of a portion of water $(10 \%$ of the total volume of the medium).

\section{Patents}

This work has been included in a patent application by Hiroshima University.

Supplementary Materials: The following supporting information can be downloaded at: https: / / www.mdpi.com/article/10.3390/gels8030154/s1, Figure S1: Langmuir adsorption isotherm plot for the acetic acid adsorption by AQ11.

Author Contributions: Conceptualization, J.K., T.G. and Y.N.; methodology, J.K. and T.G.; validation, J.K. and T.G.; investigation, J.K. and T.G.; resources, T.G. and Y.N.; data curation, J.K.; writingoriginal draft preparation, J.K.; writing-review and editing, J.K., T.G. and Y.N.; visualization, J.K.; supervision, T.G. and Y.N.; project administration, J.K., T.G. and Y.N.; funding acquisition, Y.N. All authors have read and agreed to the published version of the manuscript.

Funding: This research was partly based on results obtained from a project, JPNP16002, subsidized by the New Energy and Industrial Technology Development Organization (NEDO). The APC was also funded by the project, JPNP16002, of NEDO.

Institutional Review Board Statement: Not applicable.

Informed Consent Statement: Not applicable.

Data Availability Statement: Electronic supporting information is available.

Conflicts of Interest: Junya Kato, Takehiko Gotoh and Yutaka Nakashimada have a patent pending for this work.

\section{References}

1. Merli, G.; Becci, A.; Amato, A.; Beolchini, F. Acetic acid bioproduction: The technological innovation change. Sci. Total Environ. 2021, 798, 149292. [CrossRef] [PubMed]

2. Morales-Vera, R.; Crawford, J.; Dou, C.; Bura, R.; Gustafson, R. Techno-Economic Analysis of Producing Glacial Acetic Acid from Poplar Biomass via Bioconversion. Molecules 2020, 25, 4328. [CrossRef] [PubMed]

3. Yates, M.R.; Barlow, C.Y. Life cycle assessments of biodegradable, commercial biopolymers-A critical review. Resour. Conserv. Recycl. 2013, 78, 54-66. [CrossRef]

4. Venkata Mohan, S.; Modestra, J.A.; Amulya, K.; Butti, S.K.; Velvizhi, G. A Circular Bioeconomy with Biobased Products from CO 2 Sequestration. Trends Biotechnol. 2016, 34, 506-519. [CrossRef] 
5. Ma, X.; Liang, H.; Panda, S.; Fung, V.K.Y.; Zhou, J.F.J.; Zhou, K. C2 feedstock-based biomanufacturing of value-added chemicals. Curr. Opin. Biotechnol. 2021, 73, 240-245. [CrossRef]

6. Budsberg, E.; Morales-Vera, R.; Crawford, J.T.; Bura, R.; Gustafson, R. Production routes to bio-acetic acid: Life cycle assessment. Biotechnol. Biofuels 2020, 13, 154. [CrossRef]

7. Blank, L.M.; Narancic, T.; Mampel, J.; Tiso, T.; O'Connor, K. Biotechnological upcycling of plastic waste and other non-conventional feedstocks in a circular economy. Curr. Opin. Biotechnol. 2020, 62, 212-219. [CrossRef]

8. Wang, J.; Lin, M.; Xu, M.; Yang, S.T. Anaerobic Fermentation for Production of Carboxylic Acids as Bulk Chemicals from Renewable Biomass. Adv. Biochem. Eng. Biotechnol. 2016, 156, 323-361. [CrossRef]

9. Schuchmann, K.; Muller, V. Autotrophy at the thermodynamic limit of life: A model for energy conservation in acetogenic bacteria. Nat. Rev. Microbiol. 2014, 12, 809-821. [CrossRef]

10. Schuchmann, K.; Muller, V. Energetics and Application of Heterotrophy in Acetogenic Bacteria. Appl. Environ. Microbiol. 2016, 82, 4056-4069. [CrossRef]

11. Ercengiz Yildirim, M.; Demiral, H. Recovery of acetic acid from waste streams by extractive distillation. Water Sci. Technol. 2003, 47, 183-188. [CrossRef]

12. Lee, E.J.; Kim, Y.H. Energy saving in acetic acid process using an azeotropic distillation column with a side stripper. Chem. Eng. Commun. 2018, 205, 1311-1322. [CrossRef]

13. Wang, G.; Wang, D.I. Elucidation of Growth Inhibition and Acetic Acid Production by Clostridium thermoaceticum. Appl. Environ. Microbiol. 1984, 47, 294-298. [CrossRef]

14. Jin, Z.; Yang, S.T. Extractive fermentation for enhanced propionic acid production from lactose by Propionibacterium acidipropionici. Biotechnol. Prog. 1998, 14, 457-465. [CrossRef]

15. Safi, S.R.; Gotoh, T.; Iizawa, T.; Nakai, S. Development and regeneration of composite of cationic gel and iron hydroxide for adsorbing arsenic from ground water. Chemosphere 2019, 217, 808-815. [CrossRef]

16. Safi, S.R.; Senmoto, K.; Gotoh, T.; Iizawa, T.; Nakai, S. The effect of $\gamma$-FeOOH on enhancing arsenic adsorption from groundwater with DMAPAAQ + FeOOH gel composite. Sci. Rep. 2019, 9, 11909. [CrossRef] [PubMed]

17. Safi, S.R.; Gotoh, T. Removal of Manganese Using Polymer Gel Composites. Mater. Proc. 2020, 4, 68. [CrossRef]

18. Safi, S.R.; Gotoh, T. Simultaneous Removal of Arsenic and Manganese from Synthetic Aqueous Solutions Using Polymer Gel Composites. Nanomaterials 2021, 11, 1032. [CrossRef]

19. Song, Y.; Gotoh, T.; Nakai, S. Synthesis of Oxidant Functionalised Cationic Polymer Hydrogel for Enhanced Removal of Arsenic (III). Gels 2021, 7, 197. [CrossRef]

20. Ion Exchange Resins. Available online: https://www.diaion.com/en/products/ion_exchange_resins/strongly_basic_anion/ index.html (accessed on 10 January 2022).

21. Lopez-Garzon, C.S.; Straathof, A.J. Recovery of carboxylic acids produced by fermentation. Biotechnol. Adv. 2014, 32, 873-904 [CrossRef]

22. Hassan, M.A.; Shirai, Y.; Umeki, H.; Yamazumi, H.; Jin, S.; Yamamoto, S.; Karim, M.I.A.; Nakanishi, K.; Hashimoto, K. Acetic Acid Separation from Anaerobically Treated Palm Oil Mill Effluent by Ion Exchange Resins for the Production of Polyhydroxyalkanoate by Alcaligenes eutrophus. Biosci. Biotechnol. Biochem. 2014, 61, 1465-1468. [CrossRef]

23. da Silva, A.H.; Miranda, E.A. Adsorption/Desorption of Organic Acids onto Different Adsorbents for Their Recovery from Fermentation Broths. J. Chem. Eng. Data 2013, 58, 1454-1463. [CrossRef]

24. Chen, C.; Zhang, X.; Liu, C.; Wu, Y.; Zheng, G.; Chen, Y. Advances in downstream processes and applications of biological carboxylic acids derived from organic wastes. Bioresour. Technol. 2021, 346, 126609. [CrossRef]

25. Arafiles, K.H.; Iwasaka, H.; Eramoto, Y.; Okamura, Y.; Tajima, T.; Matsumura, Y.; Nakashimada, Y.; Aki, T. Value-added lipid production from brown seaweed biomass by two-stage fermentation using acetic acid bacterium and thraustochytrid. Appl. Microbiol. Biotechnol. 2014, 98, 9207-9216. [CrossRef]

26. Atasoy, M.; Owusu-Agyeman, I.; Plaza, E.; Cetecioglu, Z. Bio-based volatile fatty acid production and recovery from waste streams: Current status and future challenges. Bioresour. Technol. 2018, 268, 773-786. [CrossRef]

27. Miura, T.; Kita, A.; Okamura, Y.; Aki, T.; Matsumura, Y.; Tajima, T.; Kato, J.; Nakashimada, Y. Evaluation of marine sediments as microbial sources for methane production from brown algae under high salinity. Bioresour. Technol. 2014, 169, 362-366. [CrossRef] [PubMed]

28. Kato, J.; Takemura, K.; Kato, S.; Fujii, T.; Wada, K.; Iwasaki, Y.; Aoi, Y.; Matsushika, A.; Murakami, K.; Nakashimada, Y. Metabolic engineering of Moorella thermoacetica for thermophilic bioconversion of gaseous substrates to a volatile chemical. AMB Express 2021, 11, 59. [CrossRef]

29. Tanner, R.S.; Miller, L.M.; Yang, D. Clostridium ljungdahlii sp. nov., an acetogenic species in clostridial rRNA homology group I. Int. J. Syst. Bacteriol. 1993, 43, 232-236. [CrossRef]

30. Tanner, R.S. Monitoring Sulfate-Reducing Bacteria-Comparison of Enumeration Media. J. Microbiol. Methods 1989, 10, 83-90. [CrossRef]

31. Hungate, R.E. Chapter IV A Roll Tube Method for Cultivation of Strict Anaerobes. In Methods in Microbiology; Academic Press: Cambridge, MA, USA, 1969; pp. 117-132. 